\title{
Stress Hyperglycemia as First Sign of Asymptomatic Type 1 Diabetes: An Instructive Case and Literature Review
}

\section{Wei-De Wang}

Tri-Service General Hospital

Chun-Hao Chu

Tri-Service General Hospital

Chiung-Hsi Tien

Tri-Service General Hospital

Shuo-Yu Wang

Kaohsiung Medical University Chung Ho Memorial Hospital

Shih-Yao Liu

National Taiwan University Hospital

Chien-Ming Lin ( $\nabla$ ming.sandra@msa.hinet.net )

Tri-Service General Hospital https://orcid.org/0000-0001-7525-5743

\section{Case report}

Keywords: children, hyperglycemia, stress, type 1 diabetes mellitus

Posted Date: February 23rd, 2021

DOl: https://doi.org/10.21203/rs.3.rs-229675/v1

License: (1) This work is licensed under a Creative Commons Attribution 4.0 International License. Read Full License 


\section{Abstract}

\section{Background:}

Stress hyperglycemia ( $\mathrm{SH}$ ) is considered a transient manifestation and routine diagnostic evaluation was thought to be unnecessary due to the lack of definite correlation with diabetes mellitus (DM). Although $\mathrm{SH}$ was usually benign and long-term treatment was superfluous, it might be the first sign of insulinopenic status such as type 1 DM (T1DM).

\section{Case presentation:}

We reported a boy with acute asthma attack presented incidentally with high blood glucose levels exceeding $300 \mathrm{mg} / \mathrm{dL}$ and obvious glycemic variability. Sustained hyperglycemic duration lasting longer than 48 hours was also noticed. To elucidate his unique situation, glucagon test and insulin autoantibody survey were done which showed insulinopenia with positive anti-insulin antibody and glutamic acid decarboxylase antibody despite the absence of overt DM symptoms and signs.

\section{Conclusions:}

This case highlights that $\mathrm{SH}$ might be a prodromal presentation in T1DM children, especially when accompanied simultaneously with extreme hyperglycemia, apparent glucose variability, as well as prolonged hyperglycemic duration.

\section{Background}

Stress hyperglycemia ( $\mathrm{SH}$ ) is a common clinical manifestation in children with acute illness. It is caused by the increased levels of cortisol, catecholamine and proinflammatory cytokines (TNF-a, IL-1 and IL-6) mediated by the hypothalamic-pituitary-adrenal axis and the sympathoadrenal system. Since the physiological response of $\mathrm{SH}$ increases the glucose uptake of the brain and immune system at a time of stress which in turn enhances the chances of survival, the meticulous investigation and aggressive management to SH were thought to be unnecessary in clinical practice ${ }^{1}$. The prevalence of hyperglycemia, defined as glucose level $\geqq 150 \mathrm{mg} / \mathrm{dl}$, has been reported to be ranged from 3.8-4.9\% children in the emergency department ${ }^{2-4}$. On the other hand, among ill children in intensive care unit (ICU), SH accounted for $36.6 \%$ and $44.5 \%$ of them at the initial time and within 24 hours of the admission, respectively ${ }^{5}$. Because the $\mathrm{SH}$ seems associated with the severity of underlying disease, it was usually regarded as a benign phenomenon in acute illness. However, whether the coexistence of other pathogenic etiology could mask or aggravate SH has never been emphasized in the literature.

Previous studies showed no obvious association between $\mathrm{SH}$ and type 1 diabetes mellitus (T1DM) ${ }^{2,3,6-}$ 10 (Table 1); therefore, the routine workup for children with SH to confirm T1DM is not recommended while there is no overt signs and/or symptoms of DM. To add a new dimension to the physiological role of $\mathrm{SH}$, we herein reported an asthmatic boy having unique $\mathrm{SH}$ with manifestations of extreme 
hyperglycemia, glucose variability (GV), and prolonged hyperglycemic duration, finally confirmed as T1DM. This instructive case highlights an unusual pattern of $\mathrm{SH}$ with possible hidden pathogenesis and further investigation should be considered for precise early diagnosis to prevent subsequent diabetic ketoacidosis.

\section{Case Presentation}

An 8-year-2-month old Taiwanese boy presented with dyspnea for one day. He had no preceding symptoms such as polyphagia, polydipsia, polyuria, or body weight loss during this episode. His past medical history is notable for bronchial asthma and allergic rhinitis without using regular medication. Family history revealed no T1DM or T2DM in family members. Two days before admission, he was noted to have runny nose, productive cough and fever. He was treated with antitussives and antipyretics at a local clinic initially. Because dyspnea along with decreased oral intake was noticed one day later, he was sent to primary healthcare center where inhaled terbutaline sulfate and intramuscular dexamethasone were given in consideration of acute exacerbation of bronchial asthma (AEBA). After treatment, laboratory tests showed no acidosis or alkalosis; however, hyperglycemia was noticed (Table 2). Owing to persistent dyspnea, he was referred to our hospital. 
Table 2

Laboratory data of patient

\section{At primary healthcare center}

\section{Biochemistry}

Glucose $381 \mathrm{mg} / \mathrm{dL}$

$\mathrm{Na}^{+} \quad 133 \mathrm{mmol} / \mathrm{L}$

$\mathrm{K}^{+} \quad 4.3 \mathrm{mmol} / \mathrm{L}$

Ketone $0.7 \mathrm{mmol} / \mathrm{L}$

CRP $\quad 0.5 \mathrm{mg} / \mathrm{dL}$

\section{On admission}

BH $127 \mathrm{~cm}$ (25-50 th percentile), BW $23 \mathrm{~kg}$ ( $15^{\text {th }}$ percentile), BT $37.1^{\circ} \mathrm{C}, \mathrm{HR} 116$ beats $/ \mathrm{min}$ RR 32 breaths/min, $\mathrm{BP} 115 / 64$ mmHg, SpO $299 \%$ (nasal cannula with $\mathrm{O}_{2}$ flow rate $3 \mathrm{~L} / \mathrm{min}$ )

\section{Blood cell count}

WBC $10690 / \mu \mathrm{L}$

$\mathrm{Hb} \quad 13 \mathrm{~g} / \mathrm{dL}$

Plt $25.8 \times 10^{4} / \mu \mathrm{L}$

Neutrophil $\quad 91 \%$

Lymphocyte $\quad 6.7 \%$

Biochemistry

Glucose $373 \mathrm{mg} / \mathrm{dL}$

$\mathrm{Na}^{+} \quad 134 \mathrm{mmol} / \mathrm{L}$

$\mathrm{K}^{+} \quad 4.1 \mathrm{mmol} / \mathrm{L}$

$\mathrm{Cl}^{-} \quad 98 \mathrm{mmol} / \mathrm{L}$

AST $\quad 14 \mathrm{IU} / \mathrm{L}$

ALT $8 \mathrm{IU} / \mathrm{L}$

BUN $12 \mathrm{mg} / \mathrm{dL}$

Cre $\quad 0.5 \mathrm{mg} / \mathrm{dL}$

Ketone $0.9 \mathrm{mmol} / \mathrm{L}$
Urinalysis

$\begin{array}{lll}(4000-12000) & \mathrm{pH} & 5.0\end{array}$

(11.5-14.5)

$\left(15 \times 10^{4}-40 \times 10^{4}\right)$

(54-62)

(25-33)

Glucose

Ketone body

$4+$

$2+$

Occult blood

Strip WBC

Arterial blood gas analysis

(70-100)

(136-145)

$(3.5-5.1)$

(98-107)

$(<50)$

$(<45)$

(5-18)

(0.3-0.7)

$(<0.6)$
(7.32-7.43)

(38-49)

(30-50)

(22-29)

$(-4-+2)$ 


\begin{tabular}{|c|c|c|c|c|}
\hline $\mathrm{HbA} 1 \mathrm{C} \quad 7.7 \%$ & $(4.0-5.7)$ & & & \\
\hline Islet autoantibodies & & Glucagon & stimulation te & \\
\hline Insulin Ab $5.7 \% \mathrm{~B} / \mathrm{T}$ & $(<5.5)$ & Time & C-peptide & \\
\hline Anti-GAD $\quad 7.5 \mathrm{U} / \mathrm{mL}$ & $(<1.0)$ & 0 minute & $0.43 \mathrm{ng} / \mathrm{ml}$ & $(>0.5)$ \\
\hline Anti-TPO $15.2 \mathrm{U} / \mathrm{mL}$ & $(<35)$ & 6 minute & $1.16 \mathrm{ng} / \mathrm{ml}$ & $(>1.8)$ \\
\hline Anti-TG $\quad 5.0 \mathrm{U} / \mathrm{mL}$ & $(<20)$ & & & \\
\hline $\begin{array}{l}\text { Ab, antibody; Anti-GAD } \\
\text { antibody; Anti-TG, ant } \\
\text { aminotransferase; } \mathrm{BE} \text {, } \\
\text { blood urea nitrogen; } \mathrm{B} \\
\text { hemoglobin; } \mathrm{HbA} \mathrm{C} \mathrm{C}, \mathrm{h} \\
\text { respiratory rate; } \mathrm{SaO}_{2} \text {, } \\
\text { blood cells }\end{array}$ & $\begin{array}{l}\text { utamic a } \\
\text { obulin a } \\
\text { cess; B } \\
\text { weight; } \\
\text { bin A1c; } \\
\text { oxygen }\end{array}$ & $\begin{array}{l}\text { e antibody } \\
\text { artate amir } \\
\text { blood pres } \\
\text { reatinine; } \\
\text { potassiun } \\
\mathrm{O}_{2} \text { saturati }\end{array}$ & $\begin{array}{l}\text {; Anti-TPO, ar } \\
\text { hotransferase } \\
\text { ssure; BT, bod } \\
\text { CRP, C-reactiv } \\
\text { n; Na+, sodiur } \\
\text { ion by pulse c }\end{array}$ & $\begin{array}{l}\text { id peroxidase } \\
\text { lanine } \\
\text { erature; BUN, } \\
\text { n; Hb, } \\
\text { latelet; RR, } \\
\text {; WBC, white }\end{array}$ \\
\hline
\end{tabular}

On examination, use of accessory muscle and bilateral diffuse wheezing were noticed. There was no acanthosis nigricans over posterior neck or axillae. The thyroid was non-palpable. Laboratory tests showed hyperglycemia, ketonuria and ketonemia (Table 2). Chest radiograph revealed bilateral pulmonary infiltration. Under impression of AEBA, he was admitted to pediatric ICU (PICU).

On observing hyperglycemia, exclusively half-normal saline was infused on the first day of hospitalization. Inhaled beta-2 agonists and intravenous corticosteroids were also given. Nevertheless, blood glucose monitoring disclosed fluctuating hyperglycemia. Although this $\mathrm{SH}$ might result from AEBA per se and/or medication, his baseline blood glucose levels were inexplicably higher than $150 \mathrm{mg} / \mathrm{dL}$ within the first 24 hours and frequently rose above $300 \mathrm{mg} / \mathrm{dL}$ or even $400 \mathrm{mg} / \mathrm{dL}$ (Fig. 1). The delta blood glucose levels $(\triangle B G)$ could reach 150 to $300 \mathrm{mg} / \mathrm{dL}$ in a single hour, suggesting extremely high $\mathrm{GV}$. Moreover, blood glucose exceeding $150 \mathrm{mg} / \mathrm{dL}$ could be detected even at 48 hours after admission, indicating prolonged hyperglycemic duration. To elucidate this unusual fluctuation of glucose values, further investigations were done which showed increased hemoglobin A1c (HbA1c), positive islet autoantibodies, and insulinopenia in glucagon test (Table 2). Finally, he was diagnosed as T1DM despite the absence of classical DM symptoms.

\section{Discussion And Conclusions}

$\mathrm{SH}$ is regarded as benign and transient hyperglycemia during acute stress. Accumulating studies have demonstrated that $\mathrm{SH}$ was unrelated to T1DM, thus rendering routine confirmatory investigation

unnecessary ${ }^{2,3,6-10}$. Furthermore, extreme $S H(E S H)$, glucose levels $\geq 300 \mathrm{mg} / \mathrm{dL}$, was rarely seen in children; and it was also unrelated to subsequent $\mathrm{DM}^{10}$. Crucially, previous studies showed the ESH subjects exhibited merely $13 \%$ ketonuria ${ }^{10}$. In view of this, ketonuria in our young boy might be taken as a 
feature of glucose dysregulation in that ketone body forms rapidly in insufficient insulin environment. However, the critical timing to elucidate the underlying etiopathology of $\mathrm{SH}$ was still inconclusive, the current latent T1DM case is thus an exceptional didactic experience worthy of attention.

In addition to AEBA per se, beta-2 agonists and corticosteroids also increase blood glucose mediated by promoting gluconeogenesis. Accordingly, previous studies regarding $\mathrm{SH}$ almost excluded beta-2 agonists and corticosteroids intervention ${ }^{2,3,8,9}$; therefore, asthmatic children with underlying DM might be excluded and then underestimated. Interestingly, asthma and T1DM are both immune-mediated disease but their association was not fully clarified. It was reported that children with asthma increase the risk of subsequent T1DM development by $41 \%$ when compared to normal population ${ }^{11}$. To date, there were only two studies on a total of 33 asthmatic children exploring the relationship between transient hyperglycemia and asthma, but none of the subjects was diagnosed to have DM eventually 7,10 .

Likewise, in our patient, bronchodilator and steroid might contribute to hyperglycemia and aggravate the severity of $\mathrm{SH}$; hence, drug effect on glucose metabolism should be taken into consideration. Burgess $\mathrm{C}$. et al. reported that only high doses of inhaled beta- 2 agonist can significantly increase blood glucose to the peak level of $133 \mathrm{mg} / \mathrm{dL}$ after 5 hours of treatment in mild-to-moderate asthma subjects ${ }^{12}$. Another study showed that asthmatic patients had a peak value of glucose $293 \mathrm{mg} / \mathrm{dL}$ after 4 hours of combined treatment with beta- 2 agonist and corticosteroid ${ }^{13}$. In the present case, extreme values of blood glucose were inconsistent with the time point of beta-2 agonists and corticosteroids intervention (Fig. 1). Moreover, the inexplicably higher glucose concentration ( $\geq 300 \mathrm{mg} / \mathrm{dL})$ than those in previous studies, which together supported that dysglycemia of our case might be caused not only by acute stress and drug effect but also by underlying insulinopenia. In addition to peak blood glucose, the duration of $\mathrm{SH}$ could be another crucial clue for early detection of latent DM. It has been reported that $67 \%$ of ESH subjects normalized their blood glucose levels below $150 \mathrm{mg} / \mathrm{dL}$ within 48 hours and none of them was subsequently diagnosed with $\mathrm{DM}^{10}$. Similarly, Gupta et al. also demonstrated the restoration of SH could be observed within 24 hours in all enrolled children with illness and the result of oral glucose tolerance tests done for $86 \%$ participants were normal ${ }^{2}$. In the present case, blood glucose above $150 \mathrm{mg} / \mathrm{dL}$ was detected even at 48 hours after admission (Fig. 1), indicating that this prolonged SH might be caused by latent DM.

To elucidate the pattern of glucose fluctuation under psychiatric stress, T1DM animal models under a predator stress circumstance showed the SH was characterized as "fast and slow" pattern, in which blood glucose rapidly increased and slowly decreased thereafter ${ }^{14}$. Although we cannot fully extrapolate the animal results to humans, blood glucose levels of the present case indeed rapidly increased from 174 $\mathrm{mg} / \mathrm{dl}$ to $400 \mathrm{mg} / \mathrm{dL}$ within 2 hours (9th -11th hours after admission), maintained peak levels above 400 $\mathrm{mg} / \mathrm{dL}$ for 5 hours (11th -15th hours after admission) and then decreased slowly to $89 \mathrm{mg} / \mathrm{dL}$ (Fig. 1), suggesting a human "fast and slow" pattern along with prolonged SH course in insulinopenic status. 
Although $\mathrm{HbA1c}$ was a pivotal biomarker of long-term glycemic control with the usefulness to reflect the cumulative glycemic history of the preceding two to three months ${ }^{15}$, it cannot tell GV to clinicians. It has been reported that GV was associated with diabetes complication and increased mortality rate in PICU ${ }^{16}$, 17. Hanefeld et al. monitored blood glucose values with continuous glucose measurement systems (CGMS) in abnormal glucose tolerance subjects and control ones and demonstrated a significantly higher amplitude of glucose excursion and standard deviation (SD) in those with abnormal glucose tolerance, suggesting higher $\mathrm{GV}^{18}$. Another study focusing on children with positive islet autoantibodies (high risk to future T1DM) revealed those with blood glucose above $140 \mathrm{mg} / \mathrm{dL}$ accounted for over $20 \%$ study time during a 5- to 7- day -period of CGMS monitor could be used to predict the future development of DM. Compared to patients with negative antibody, a higher SD of blood glucose was noted in those with positive islet autoantibodies ${ }^{19}$.

Owing to unconfirmed diagnosis of DM at admission, regular stick blood glucose test was performed for our patient to evaluate his GV under stress instead of real-time CGMS. Significant change of blood glucose was noticed initially after stress exposure; however, obvious variation unexpectedly existed after the resolution of acute stress (Fig. 1). This interesting finding illuminated persistent high GV after stress might be a potent risk factor for underlying T1DM, but further study with more patients is needed to confirm our current findings.

To our knowledge, there has been no prospective study exploring the difference in SH between diabetic and nondiabetic children. This first case highlights an important but still complex relationship between $\mathrm{SH}$ (glucose dysregulation) and subclinical T1DM (insulinopenia). We suggest that clinicians should be aware of pathological SH, particularly when it was characterized by features such as $\mathrm{ESH}(>300 \mathrm{mg} / \mathrm{dl})$, high GV even after acute phase of illness, prolonged hyperglycemic duration (longer than 48 hours) or ketonuria (urine ketone $\geq 2+$ ), all suggesting that dysglycemia might result from latent diabetes. Then further investigations to traditionally benign SH should be conducted even there were no clinical signs or symptoms of diabetes.

\section{Abbreviations}

AEBA: Acute exacerbation of bronchial asthma; CGMS: Continuous glucose measurement systems; DM: Diabetes mellitus; ESH: Extreme stress hyperglycemia; GV: Glucose variability; HbA1c: Hemoglobin A1c; ICU: Intensive care unit; PICU: Pediatric intensive care unit; SD: Standard deviation; SH: Stress hyperglycemia; T1DM: Type 1 diabetes mellitus

\section{Declarations}

\section{Ethics approval and consent to participate}

Not applicable. 


\section{Consent for publication}

Consent for publication from the parents was obtained.

\section{Availability of data and materials}

Not applicable.

\section{Competing interests}

The authors declare that they have no competing interests.

\section{Funding}

This study was supported in part by a grant from the Research Fund of Tri-Service General Hospital (TSGH-E-110187).

\section{Authors' contributions}

WDW conceptualized the study, collected data, drafted the initial manuscript, and reviewed and revised the manuscript. CHC, CHT, SYW, SYL collected data, carried out the initial analyses, and reviewed and revised the manuscript. CML conceptualized the study, coordinated and supervised data collection, and provided critical editing and revision to the final drafts of the report.

\section{Acknowledgements}

Not applicable.

\section{References}

1. Marik PE, Bellomo RJCC. Stress hyperglycemia: an essential survival response! 2013;17(2):305.

2. Gupta P, Natarajan G, Agarwal KJTIJoP. Transient hyperglycemia in acute childhood illnesses: to attend or ignore? 1997;64(2):205-10.

3. Bhisitkul DM, Morrow AL, Vinik Al, Shults J, Layland JC, Rohn RJTJop. Prevalence of stress hyperglycemia among patients attending a pediatric emergency department. 1994;124(4):547-51.

4. Valerio G, Franzese A, Carlin E, Pecile P, Perini R, Tenore AJAP. High prevalence of stress hyperglycaemia in children with febrile seizures and traumatic injuries. 2001;90(6):618-22.

5. Faustino EV, Apkon MJTJop. Persistent hyperglycemia in critically ill children. 2005;146(1):30-4.

6. Shehadeh N, On A, Kessel I, Perlman R, Even L, Naveh T, et al. Stress hyperglycemia and the risk for the development of type I diabetes. De Gruyter; 1997.

7. Herskowitz-Dumont R, Wolfsdorf JI, Jackson RA, Eisenbarth GSJTJop. Distinction between transient hyperglycemia and early insulin-dependent diabetes mellitus in childhood: a prospective study of incidence and prognostic factors. 1993;123(3):347-54. 
8. Eshraghi P, Bagheri S, Kamel SJIJoP. Association of Pediatric Stress Hyperglycemia with Insulin Metabolism Disorders. 2014;2(1):83-7.

9. Bhisitkul DM, Vinik Al, Morrow AL, She J-X, Shults J, Powers AC, et al. Prediabetic markers in children with stress hyperglycemia. 1996;150(9):936-41.

10. Weiss SL, Alexander J, Agus MSJPec. Extreme stress hyperglycemia during acute illness in a pediatric emergency department. 2010;26(9):626.

11. Metsälä J, Lundqvist A, Virta LJ, Kaila M, Gissler M, Virtanen SM, et al. The association between asthma and type 1 diabetes: a paediatric case-cohort study in Finland, years 1981-2009. International journal of epidemiology. 2018;47(2):409-16.

12. Burgess C, Ayson M, Rajasingham S, Crane J, Della Cioppa G, Till M. The extrapulmonary effects of increasing doses of formoterol in patients with asthma. European journal of clinical pharmacology. 1998;54(2):141-7.

13. Smith A, Banks J, Buchanan K, Cheong B, Gunawardena KJQAIJoM. Mechanisms of abnormal glucose metabolism during the treatment of acute severe asthma. 1992;82(1):71-80.

14. Chang J-S, You Y-H, Park S-Y, Kim J-W, Kim H-S, Yoon K-H, et al. Pattern of stress-induced hyperglycemia according to type of diabetes: a predator stress model. 2013;37(6):475-83.

15. Association AD. 6. Glycemic Targets: Standards of Medical Care in Diabetes-2020. Diabetes Care. 2020;43(Supplement 1):S66-S76.

16. Hirshberg E, Larsen G, Van Duker H. Alterations in glucose homeostasis in the pediatric intensive care unit: Hyperglycemia and glucose variability are associated with increased mortality and morbidity. Pediatric Critical Care Medicine. 2008;9(4):361-6.

17. Wintergerst KA, Buckingham B, Gandrud L, Wong BJ, Kache S, Wilson DMJP. Association of hypoglycemia, hyperglycemia, and glucose variability with morbidity and death in the pediatric intensive care unit. 2006;118(1):173-9.

18. Hanefeld M, Sulk S, Helbig M, Thomas A, Köhler CJJods, technology. Differences in glycemic variability between normoglycemic and prediabetic subjects. 2014;8(2):286-90.

19. Steck AK, Dong F, Taki I, Hoffman M, Klingensmith GJ, Rewers MJ. Early hyperglycemia detected by continuous glucose monitoring in children at risk for type 1 diabetes. Diabetes care. 2014;37(7):2031-3.

\section{Table}

Due to technical limitations, table $1 \mathrm{xlsx}$ is only available as a download in the Supplemental Files section.

\section{Figures}




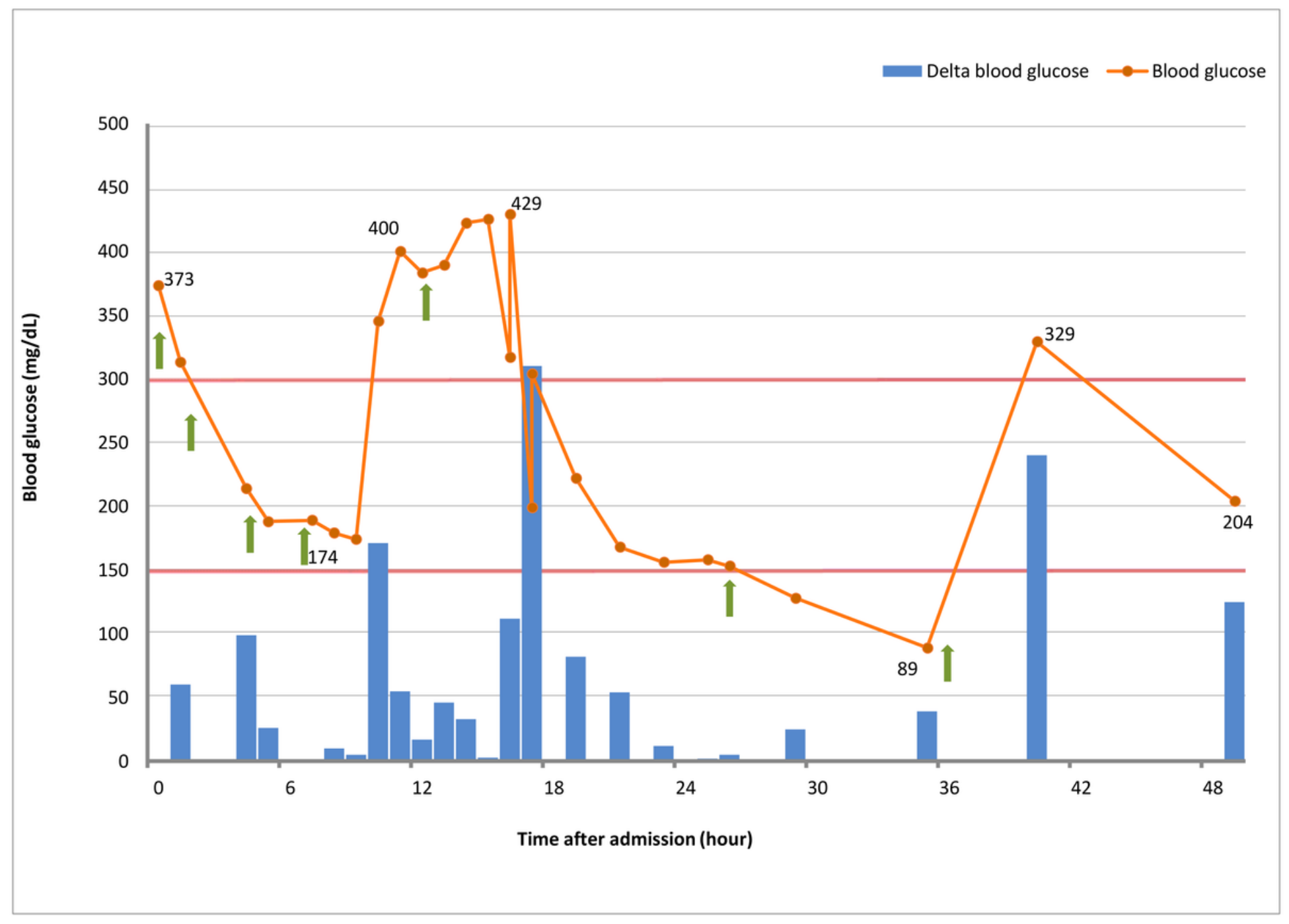

Figure 1

Blood glucose monitoring of patient after admission Blood glucose concentration (orange line and dots) measured by regular fingerstick testing over two consecutive days after admission. Delta blood glucose (blue bars) was defined as change in blood glucose values between two adjacent time points, which also represents the trend of glycemic variability over time. Green arrows indicate the use of beta-2 agonists or corticosteroids.

\section{Supplementary Files}

This is a list of supplementary files associated with this preprint. Click to download.

- Table120210209.xIsx 